\title{
Differential genetic etiology of reading disability as a function of mathematics performance
}

\author{
S. D. CASTO ${ }^{1}$, B. F. PENNINGTON ${ }^{2}$, J. G. LIGHT ${ }^{3}$ and J. C. DEFRIES ${ }^{1}$ \\ 'Institute for Behavioral Genetics, University of Colorado, Boulder, Colorado; ${ }^{2}$ Department \\ of Psychology. University of Denver, Denver, Colorado; ${ }^{3}$ Institute for Social Research, \\ University of Michigan, Ann Arbor, Michigan, USA
}

\begin{abstract}
In order to assess the etiology of reading disability as a function of mathematics performance, data from 168 monozygotic (MZ) and 127 same-sex dizygotic (DZ) twin pairs in which at least one member of each pair was reading-disabled were subjected to quantitative genetic analyses. $\mathrm{MZ}$ and $\mathrm{DZ}$ concordance rates for reading disability were computed for different levels of mathematics performance, and reading performance data were fitted to an extension of the basic multiple regression model for the analysis of selected twin data. Results of these analyses suggest that genetic factors may be especially salient as a cause of reading disability in children with borderline deficits in mathematics performance: thus, mathematics performance may be a valid dimension for diagnosing subtypes of reading disability.
\end{abstract}

KEY WORDS: Differential diagnosis, Etiology, Genetics, Mathematics performance, Reading disability, Twins

\section{INTRODUCTION}

Although the field of learning disabilities has grown to represent over one third of the children who receive special education, the condition remains one of the least understood disorders that affect school-age children:

The field has been, and continues to be, beset by pervasive and, at times, contentious disagreements about definitions, diagnostic criteria, assessment practices, teaching/intervention procedures and educational policy. Nevertheless, difficulties and failures in the past must not deter new efforts to develop conceptualizations that provide a critical description and characterization of learning disabilities. Indeed . . the development of a reliable and valid definition and classification system for learning disabilities is the most pressing scientific goal currently facing the field. (Lyon 1993: XVII) Fletcher et al. (1993) have advocated that discrepancies in the development of various academic areas may be used to classify learning disabilities. For example, Fletcher (1985) and Rourke (1989) compared cognitive, behavioral, and electrophysiological measures in children with impairments in reading and spelling (RS), arithmetic (A), and reading, spelling, and arithmetic (RSA). Children in the RS and A groups were found to be relatively homogeneous and to have reliably different cognitive profiles. Thus, although the comorbidity between reading and mathematics disabilities is substantial (Light \& 
DeFries 1995), mathematics performance may be an important dimension for diagnosing subtypes of learning disabilities (Fletcher, Morris \& Francis 1991).

Siegel \& Heaven (1986) attributed the poor math performance of readingdisabled (RD) children to the same symbol processing deficit that affects their reading skills. They noted that written arithmetic tests require skills likely to be deficient in RD children, including attention, short-term memory, and response to printed words and/or symbols. In contrast, Strang \& Rourke (1985) suggested that the poor performance of learning-disabled (LD) children on measures of math achievement may simply be due to lack of experience. They hypothesized that LD children do not receive the same level, type, or amount of math instruction as other children because they are often referred to special classes for their reading/spelling problems.

An alternative approach to validating subtypes of reading disabilities is to assess for differential genetic etiologies (Pennington, Gilger, Olson \& DeFries 1992). Results of previous research have established that reading disability is heritable at least to some extent (DeFries, Fulker \& LaBuda 1987). For example, by fitting a basic multiple regression model (DeFries \& Fulker 1985) to data from a large sample of reading-disabled twin pairs, DeFries \& Gillis (1993) found that approximately $50 \%$ of the proband reading deficits were due to genetic influences. More recently, Light \& DeFries (1995) assessed the etiology of comorbid reading and mathematics deficits in the same sample using both cross-concordance rate comparisons and a bivariate extension of the multiple regression methodology. Resulting estimates of bivariate heritability and shared environmentality were 0.26 and 0.25 , respectively, indicating that approximately one-fourth of the proband reading deficit is due to genetic factors influencing both reading and math performance, while another $25 \%$ of this deficit is due to environmental influences shared by members of twin pairs which also affect math performance. These findings suggest that both genetic and shared environmental influences contribute importantly to the observed covariance between reading and mathematics deficits.

Although both genetic and environmental influences have been found to cause reading deficits and their comorbidity with math deficits, the etiology of reading problems may differ in those subjects with or without math problems. The primary objective of the present study was to assess the differential etiology of reading deficits as a function of mathematics performance. Data from twin pairs participating in the Colorado Reading Project in which at least one member of the pair was classified as reading-disabled were subjected to concordance rate comparisons and to an extension of the basic multiple regression model for the analyses of selected twin data (DeFries \& Fulker 1985). The results of these analyscs provide evidence for a possible differential heritability of reading problems as a function of performance in mathematics. 


\section{METHODS}

Subjects. As part of the Colorado Reading Project (DeFries 1985), twin pairs were systematically ascertained through participating school districts within a 150-mile radius of Denver, Colorado. All twin pairs in a school district were first identified without regard to reading performance. Permission was then sought from the parents to review the school records of the twins for evidence of reading problems (e.g., poor reading achievement scores, referral to remedial reading programs, or reports of reading difficulty by teachers or school psychologists). Those pairs in which at least one member evidenced a school history of reading problems were then invited to participate in an extensive testing session at the University of Colorado. In addition, a comparison sample of twin pairs in which neither twin had a school history of reading problems was tested and matched to the probands by age, gender, and school district.

Twin pairs were administered a battery of psychometric tests, including subtests of the Peabody Individual Achievement Test (Reading Recognition, Reading Comprehension, Spelling, Mathematics) (PIAT; Dunn \& Markwardt 1970), and the Wechsler Intelligence Scale for Children - Revised (WISC-R; Wechsler 1974) or the Wechsler Adult Intelligence Scale - Revised (WAISR; Wechsler 1981). Diagnosis of reading disability was based in part upon a reading composite score computed for each individual. This composite was obtained by employing discriminant weights estimated from an analysis of PIAT Reading Recognition, Reading Comprehension, and Spelling data from an independent sample of 140 reading-disabled and 140 control nontwin subjects. A composite math score was computed by summing standardized PIAT Mathematics and WISC-R (or WAIS-R) Arithmetic subtest scores.

Pairs were included in the reading-disabled sample if at least one member of the pair (the proband) met each of the following criteria: (1) evidence of reading problems in school; (2) a negative discriminant reading score; (3) a score of at least 90 on either the Verbal or Performance subscales of the WISCR or WAIS-R; (4) no evidence of severe emotional or neurological problems; and (5) no uncorrected visual or auditory acuity deficits.

Zygosity of the twin pairs was determined using selected items from the Nichols \& Bilbro (1966) zygosity questionnaire which has a reported accuracy of $95 \%$. In cases of doubtful zygosity, blood samples were genotyped by the Minneapolis War Memorial Blood Bank. Data from 295 reading-disabled twin pairs, including 168 monozygotic (MZ) pairs ( 79 male, 89 female) and 127 same-sex dizygotic (DZ) pairs ( 73 male, 54 female) were analyzed for the present study. The control sample consisted of $149 \mathrm{MZ}$ (65 male, 84 female) and 99 same-sex DZ (55 male, 44 female) pairs. The mean Verbal and Performance IQ scores were 98 and 102 respectively for probands, and 112 and 111 respectively for the matched control twins. All twins ranged in age from 8 to 20 years at the time of testing (mean $=11.78$ ). 
Analysis

Concordance rates. Concordance rate comparisons have been used in previous twin studies of reading disability (Bakwin 1973; Stevenson, Graham, Fredman \& McLoughlin 1984, 1987) to assess genetic influences. In these studies, a pair was defined to be concordant if both members of the pair were readingdisabled, and discordant if only one member of the pair was reading-disabled. Although MZ twins share all their genes, $\mathrm{DZ}$ twins share only $50 \%$ of their segregating genes, on average. Thus, a higher concordance rate for $\mathrm{MZ}$ twin pairs compared to $\mathrm{DZ}$ twin pairs suggests a genetic etiology for reading disability. In the present study, probandwise concordance rates (DeFries \& Gillis 1991) for reading disability were computed for MZ and DZ twin pairs for three different levels of mathematics performance. By dividing the readingdisabled sample into classes based on their math scores, the possibility of differential genetic influences on reading disability as a function of math performance was assessed.

Multiple regression analyses. Although a comparison of $\mathrm{MZ}$ and $\mathrm{DZ}$ concordance rates provides a test of genetic etiology for dichotomous variables, a multiple regression analysis of twin data provides an alternative test of genetic etiology that is statistically more powerful for continuous variables (DeFries \& Fulker 1985, 1988). Since the MZ and DZ probands in a selected sample are ascertained because of deviant scores on a continuous measure, such as low reading performance, the scores of the cotwins are expected to regress toward the mean of the unselected population. However, this regression to the mean should differ for $M Z$ and $D Z$ cotwins to the extent that the trait is heritable. Since $M Z$ twins share all their genes, the scores of $M Z$ cotwins are expected to regress less toward the unselected population mean than those of $\mathrm{DZ}$ cotwins if the deviant scores are due, at least in part, to genetic influences.

DeFries \& Fulker (1985) formulated a basic regression model which facilitates the analysis of twin data from selected samples. This model involves the regression of a cotwin's reading score $(\mathrm{C})$ on the proband's reading score $(\mathrm{P})$ and the coefficient of relationship ( $\mathrm{R} ; \mathrm{R}=1.0$ for $\mathrm{MZ}$ twin pairs and $\mathrm{R}=0.5$ for $\mathrm{DZ}$ twin pairs):

$$
\mathrm{C}=\mathrm{B}_{1} \mathrm{P}+\mathrm{B}_{2} \mathrm{R}+\mathrm{A}
$$

where $\mathrm{A}$ is the regression constant. The $\mathrm{B}_{1}$ coefficient represents the partial regression of cotwin's score on proband's score, providing a measure of average $\mathrm{MZ}$ and $\mathrm{DZ}$ twin resemblance (LaBuda, DeFries \& Fulker 1986). More interestingly, the $B_{2}$ coefficient, the partial regression of cotwin's score on the coefficient of relationship, equals twice the difference between the means of the $M Z$ and $D Z$ cotwins, controlling for differences between the $M Z$ and $\mathrm{DZ}$ proband scores. In other words, $\mathrm{B}_{2}$ provides a direct test of genetic etiology. By transforming the data prior to multiple regression analyses (see 
DeFries \& Fulker 1988), $B_{2}$ directly estimates $h_{\mathrm{g}}^{2}$, the heritability of the proband deficit. In addition, the difference between the transformed $\mathrm{MZ}$ cotwin mean and $\mathrm{h}_{\mathrm{g}}^{2}$ provides an estimate of $\mathrm{c}_{\mathrm{g}}^{2}$, the proportion of the proband deficit due to environmental influences shared by members of twin pairs.

By fitting an extended model to the data, this multiple regression technique can be used to assess differential genetic etiology as a function of covariates such as age and gender. For the present study, the hypothesis of a differential genetic etiology for reading disability as a function of proband math scores was tested by applying the following extended model to the data:

$$
\mathrm{C}=\mathrm{B}_{1} \mathrm{P}+\mathrm{B}_{2} \mathrm{R}+\mathrm{B}_{3} \mathrm{M}+\mathrm{B}_{4} \mathrm{PM}+\mathrm{B}_{5} \mathrm{RM}+\mathrm{A}
$$

where $\mathrm{M}$ symbolizes the proband's math score or a contrast code representing a particular group of math scores. The coefficients of the PM and RM interaction terms $\left(B_{4}\right.$ and $\left.B_{5}\right)$ test for differential twin resemblance and differential $\mathbf{h}_{\mathrm{g}}^{2}$ as a function of math scores, respectively. Additional terms were then added to the model to test for quadratic effects of math performance as follows:

$$
\begin{aligned}
C= & B_{1} P+B_{2} R+B_{3} M+B_{4} P M+B_{5} R M+B_{6} M^{2}+ \\
& B_{7} P^{2}+B_{8} R M^{2}+A
\end{aligned}
$$

where the $B_{7}$ and $B_{8}$ coefficients test for differential twin resemblance and differential $h_{\mathrm{g}}^{2}$ as a quadratic function of math scores, respectively.

Subjects were those twin pairs in which at least one member of the pair met the criteria for reading disability. Since the current twin sample was ascertained using truncate selection, those pairs in which both members were diagnosed as reading-disabled were double entered for all regression analyses. Such double entry is analogous to the computation of probandwise concordance rates in which both affected members of concordant pairs are included as probands (DeFries \& Gillis 1991). Resulting computer-generated estimates of standard error and tests of significance for the regression coefficients were adjusted to correct for double entry.

\section{RESULTS}

Concordance rates. Concordance rates for reading disability were first computed without regard to math performance. Probandwise concordances rates for reading-disabled (RD) probands were $68 \%$ for $\mathrm{MZ}$ cotwins and $40 \%$ for $\mathrm{DZ}$ cotwins. This difference between the $\mathrm{MZ}$ and $\mathrm{DZ}$ concordance rates is significant $(\mathrm{z}=4.76 ; p<0.0001)$, supporting previous results suggesting a genetic etiology for reading disability.

In order to test the hypothesis of differential genetic etiology for reading problems as a function of math scores, twin pairs were placed into one of three approximately equal groups based on the composite math score (MATH) of the proband. Probands with a math score greater than or equal to -1 (MATH 
$\geqslant-1$ ) were classified as 'not math-disabled' (non-MD); those with math scores greater than or equal to -2 but less than $-1(-2 \leqslant$ MATH $<-1)$ were classified as 'borderline math-disabled' (borderline-MD); and those with math scores of less than -2 (MATH < -2) were classified as 'math-disabled' (MD). Probandwise concordance rates for reading disability for the three groups are presented in Table 1. Concordance rates for $\mathrm{MZ}$ twins are significantly higher than those for DZ twins in each of the three groups, strongly suggesting a genetic etiology for reading disability. Although these differences are fairly uniform across the three groups, the magnitudes of the actual concordance rates differ somewhat; thus the etiology of reading deficits may differ, at least to some extent, as a function of mathematics performance.

Table 1. Probandwise concordance rates by level of mathematics performance ${ }^{a}$

\begin{tabular}{llll}
\hline & Non-MD group & Borderline-MD group & MD group \\
\hline MZ & $0.58(\mathrm{~N}=82)$ & $0.75(\mathrm{~N}=110)$ & $0.70(\mathrm{~N}=63)$ \\
$\mathrm{DZ}$ & $0.33(\mathrm{~N}=58)$ & $0.44(\mathrm{~N}=61)$ & $0.43(\mathrm{~N}=40)$ \\
Significance test & $\mathrm{z}=2.18$ & $\mathrm{z}=3.23$ & $\mathrm{z}=2.32$ \\
& $(p=0.029)$ & $(p=0.001)$ & $(p=0.020)$ \\
\hline
\end{tabular}

a $\mathrm{N}$ is the number of twin pairs in each group after twin pairs concordant for RD have been double-entered, while $z$ and $p$ values are based on the number of single-cntered pairs in the study.

Multiple regression analysis. The $\mathrm{MZ}$ and $\mathrm{DZ}$ proband and cotwin reading performance (READ) scores were standardized against the mean of 496 control twins and first analyzed without regard to math performance scores. As shown in Table 2, the MZ and DZ proband READ scores are highly similar, falling over 2.5 standard deviations (SD) below the control mean. The differential regression to the mean is evident as $\mathrm{MZ}$ cotwins regress only 0.20 SD units, while DZ cotwins regress 0.91 SD units. When the proband and cotwin transformed READ scores were fitted to the basic regression model

Table 2. Mean reading performance (READ) scores

\begin{tabular}{lllllll}
\hline & & \multicolumn{2}{l}{ Standardized against controls } & & \multicolumn{2}{c}{ Transformed READ scores $^{\mathrm{b}}$} \\
Zyg & $\mathrm{N}_{\text {Pars }}{ }^{\mathrm{c}}$ & Proband & Cotwin & & Proband & Cotwin \\
\hline $\mathrm{MZ}$ & 255 & $-2.78 \pm 0.87$ & $-2.58 \pm 1.11$ & & $1.00 \pm 0.31$ & $0.93 \pm 0.40$ \\
$\mathrm{DZ}$ & 159 & $-2.72 \pm 0.90$ & $-1.81 \pm 1.42$ & & $1.00 \pm 0.33$ & $0.67 \pm 0.52$ \\
\hline
\end{tabular}

a Expressed in standard deviation units from the mean of a sample of 496 control twins.

- Scores are expressed as deviations from the READ mean of the unselected population and then divided by the difference between proband and control mean READ scores.

c Number of twin pairs following double entry of twin pairs concordant for RD. 
(Equation 1), the $B_{2}$ coefficient was significant $\left(B_{2}=h_{g}^{2}=0.52 \pm 0.09\right)$, suggesting that approximately $50 \%$ of the proband reading deficit is due to genetic factors (see Table 3 ). An estimate of $c_{g}^{2}$, the extent to which proband reading deficits are due to shared environmental influences, can be obtained by taking the difference between the transformed $\mathrm{MZ}$ cotwin mean and $\mathrm{h}_{\mathrm{g}}^{2}$. The resulting estimate of $\mathrm{c}_{\mathrm{g}}^{2}=0.41$ suggests that approximately $40 \%$ of the proband reading deficit can be attributed to environmental influences shared by members of twin pairs.

Table 3. Fit of basic regression model to transformed proband and control READ scores

\begin{tabular}{lllrl}
\hline Coefficient & Interpretation & Estimate \pm SE & \multicolumn{1}{c}{$t$} & \multicolumn{1}{c}{$p$} \\
\hline $\mathrm{B}_{1}$ & Average MZ \& DZ resemblance & $0.74 \pm 0.07$ & 10.63 & $<0.0001$ \\
$\mathrm{~B}_{2}$ & Estimate of $\mathrm{h}_{\mathrm{g}}^{2}$ & $0.52 \pm 0.09$ & 5.67 & $<0.0001$ \\
\hline
\end{tabular}

To assess the possibility of differential genetic etiology, the standardized READ scores of probands and cotwins (shown in Table 4) were compared across twin pairs divided into three groups based on the MATH score of the proband. The $\mathrm{MZ}$ and $\mathrm{DZ}$ proband READ scores are quite similar within each of the three groups and, in each case, are more than $2.5 \mathrm{SD}$ below the control mean. For each group, $M Z$ and $D Z$ twins regress differentially toward the mean of the unselected population. However, this differential regression is not uniform across the three groups. In the non-MD group, $M Z$ cotwins regress $0.39 \mathrm{SD}$ units and $\mathrm{DZ}$ cotwins regress $0.80 \mathrm{SD}$ units, while in the borderlineMD group, $\mathrm{MZ}$ cotwins regress only $0.08 \mathrm{SD}$ units and $\mathrm{DZ}$ cotwins regress 1.11 SD units. The MD group is similar to the non-MD group in that $\mathrm{MZ}$

Table 4. Mean reading performance (READ) scores by math group

\begin{tabular}{|c|c|c|c|c|c|c|}
\hline \multirow[b]{2}{*}{ Math group } & \multirow[b]{2}{*}{ Zyg } & \multirow[b]{2}{*}{$N_{\text {Pars }}^{c}$} & \multicolumn{2}{|c|}{$\begin{array}{l}\text { Standardized against } \\
\text { controls }^{\mathrm{a}}\end{array}$} & \multicolumn{2}{|c|}{$\begin{array}{l}\text { Transformed READ } \\
\text { scores }^{b}\end{array}$} \\
\hline & & & Proband & Cotwin & Proband & Cotwin \\
\hline Non-MD & $\begin{array}{l}\mathrm{MZ} \\
\mathrm{DZ}\end{array}$ & $\begin{array}{l}82 \\
58\end{array}$ & $\begin{array}{l}-2.67 \pm 0.85 \\
-2.52 \pm 0.75\end{array}$ & $\begin{array}{l}-2.28 \pm 1.06 \\
-1.72 \pm 1.31\end{array}$ & $\begin{array}{l}1.00 \pm 0.32 \\
1.00 \pm 0.30\end{array}$ & $\begin{array}{l}0.85 \pm 0.40 \\
0.68 \pm 0.52\end{array}$ \\
\hline Borderline-MD & $\begin{array}{l}\mathrm{MZ} \\
\mathrm{DZ}\end{array}$ & $\begin{array}{r}110 \\
61\end{array}$ & $\begin{array}{l}-2.76 \pm 0.86 \\
-2.77 \pm 0.94\end{array}$ & $\begin{array}{l}-2.68 \pm 1.11 \\
-1.66 \pm 1.49\end{array}$ & $\begin{array}{l}1.00 \pm 0.31 \\
1.00 \pm 0.34\end{array}$ & $\begin{array}{l}0.97 \pm 0.40 \\
0.60 \pm 0.54\end{array}$ \\
\hline MD & $\begin{array}{l}\mathrm{MZ} \\
\mathrm{DZ}\end{array}$ & $\begin{array}{l}63 \\
40\end{array}$ & $\begin{array}{l}-2.99 \pm 0.92 \\
-2.92 \pm 1.01\end{array}$ & $\begin{array}{l}-2.80 \pm 1.11 \\
-2.18 \pm 1.44\end{array}$ & $\begin{array}{l}1.00 \pm 0.31 \\
1.00 \pm 0.35\end{array}$ & $\begin{array}{l}0.94 \pm 0.37 \\
0.75 \pm 0.49\end{array}$ \\
\hline
\end{tabular}

\footnotetext{
a Expressed in standard deviation units from the mean of a sample of 496 control twins.

b Scores are expressed as deviations from the READ mean of the unselected population and then divided by the difference between proband and control mean READ scores.

c Number of twin pairs following double entry of twin pairs concordant for RD.
} 
cotwins regress $0.19 \mathrm{SD}$ units and $\mathrm{DZ}$ cotwins regress $0.74 \mathrm{SD}$ units. This pattern of differential regression to the mean among the three groups suggests a possible quadratic trend in the magnitude of genetic etiology.

As shown in Table 5, when proband and cotwin transformed READ scores were fitted to the basic regression model separately for each group (Equation 1 ), the $B_{2}$ coefficient provided differing estimates of $h_{g}^{2}$, with the estimate for the borderline-MD group (i.e., those probands with math scores in the middle range) being higher $\left(B_{2}=h_{g}^{2}=0.75\right)$ than for the other two groups $\left(h_{g}^{2}=0.35\right.$ and $h_{\mathrm{g}}^{2}=0.38$ ). These estimates suggest that approximately $75 \%$ of the proband reading deficit in the borderline-MD group is due to genetic influences compared to only about $35 \%$ in the non-MD and MD groups. The estimates of $\mathrm{c}_{\mathrm{g}}^{2}$ for the non-MD, borderline-MD, and $\mathrm{MD}$ groups are $0.50,0.22$, and 0.56 , respectively. This suggests that shared environmental influences have less of an effect on proband reading deficits for those in the borderline-MD group than for those in the other two groups.

Table 5. Fit of basic regression model to proband and control transformed READ scores for three groups differing in MATH score

\begin{tabular}{lllllr}
\hline Math group & Coefficient & Interpretation & Estimate $\pm \mathrm{SE}$ & $t$ \\
\hline \multirow{2}{*}{ Non-MD } & $\mathrm{B}_{1}$ & Average $\mathrm{MZ} \& \mathrm{DZ}$ resemblance & $0.72 \pm 0.13$ & 5.65 & $<0.0001$ \\
& $\mathrm{~B}_{2}$ & Estimate of $\mathrm{h}_{\mathfrak{g}}^{2}$ & $0.35 \pm 0.16$ & 2.19 & 0.0285 \\
\multirow{4}{*}{ Borderline-MD } & $\mathrm{B}_{1}$ & Average $\mathrm{MZ} \& \mathrm{DZ}$ resemblance & $0.69 \pm 0.11$ & 5.96 & $<0.0001$ \\
& $\mathrm{~B}_{2}$ & Estimate of $\mathrm{h}_{\mathfrak{g}}^{2}$ & $0.75 \pm 0.15$ & 4.95 & $<0.0001$ \\
$\mathrm{MD}$ & $\mathrm{B}_{1}$ & Average $\mathrm{MZ} \& \mathrm{DZ}$ resemblance & $0.79 \pm 0.12$ & 6.41 & $<0.0001$ \\
& $\mathrm{~B}_{2}$ & Estimate of $\mathrm{h}_{\mathfrak{g}}^{2}$ & $0.38 \pm 0.16$ & 2.34 & 0.0193 \\
\hline
\end{tabular}

In order to test the significance of this apparent differential genetic etiology, the data were then fit to the extended regression model (Equation 3). This model tests for differential etiology as a quadratic function of math performance by adding terms for math score (for which group-based contrast codes of $-1,0$, and +1 were used for the $M D$, borderline $M D$, and non-MD groups, respectively) and the interactions between math score and other variables of interest to control for linear effects of math ability, as well as a squared math score term and interactions to test for curvilinear effects of math ability. The results of fitting Equation 3 revealed a significant interaction between the coefficient of relationship ( $R$ ) and the squared code of the proband's math group $\left(\mathrm{M}^{2}\right)$, as shown in Table 6 . This parameter estimate $\left(B_{8}=-0.39\right.$ $\pm 0.19, p=0.04$ ) measures differential $h_{g}^{2}$ as a quadratic function of math performance and provides cvidence for differential genetic etiology among the three groups.

The data was also fit to Equation 3 using the continuously distributed composite math score (MATH) rather than dividing the subjects into groups. As shown in Table 7, when these data were fit to Equation 3, the results were in 
Table 6. Fit of extended regression model to proband and control transformed READ scores based on discontinuous math groups

\begin{tabular}{llrrr}
\hline Coefficient & Interpretation & Estimate $\pm \mathrm{SE}$ & \multicolumn{1}{c}{$p$} \\
\hline $\mathrm{B}_{2}$ & Estimate of $\mathrm{h}_{\mathrm{g}}^{2}$ when $\mathrm{M}=0$ & $0.75 \pm 0.15$ & 5.15 & $<0.0001$ \\
$\mathrm{~B}_{5}$ & Estimate of linear effect of math group on $\mathrm{h}_{\mathrm{g}}^{2}$ & $-0.01 \pm 0.12$ & -0.08 & 0.7490 \\
$\mathrm{~B}_{8}$ & Estimate of quadratic effect of math group on $\mathrm{h}_{\mathrm{g}}^{2}$ & $-0.39 \pm 0.19$ & -2.06 & 0.0394 \\
\hline
\end{tabular}

Table 7. Fit of extended regression model to proband and control transformed READ scores based on continuous MATH scores

\begin{tabular}{llrrr}
\hline Coefficient & Interpretation & Estimate $\pm \mathrm{SE}$ & $t$ & \multicolumn{1}{c}{$p$} \\
\hline $\mathrm{B}_{2}$ & Estimate of $\mathrm{h}_{\mathrm{g}}^{2}$ when $\mathrm{M}=0$ & $0.35 \pm 0.22$ & 1.56 & 0.1188 \\
$\mathrm{~B}_{5}$ & Estimate of linear effect of math group on $\mathrm{h}_{\mathrm{g}}^{2}$ & $-0.42 \pm 0.31$ & -1.37 & 0.1707 \\
$\mathrm{~B}_{\mathbf{8}}$ & Estimate of quadratic effect of math group on $\mathrm{h}_{\mathrm{g}}^{2}$ & $-0.16 \pm 0.10$ & -1.60 & 0.1096 \\
\hline
\end{tabular}

the same direction as before, but the $\mathbf{B}_{\mathbf{8}}$ coefficient was not significant for the continuous case $\left(B_{8}=-0.16 \pm 0.10, p=0.11\right)$.

The cause of this unexpected result was explored employing an outlier analysis. Although the math scores appear to be normally distributed, outliers may have had a strong influence on the bivariate relationships. The analysis identified several subjects as outliers according to criteria suggested by Judd $\&$ McClelland (1989). When the continuous data were reanalyzed omitting these outliers, the $B_{8}$ coefficient was significant $\left(B_{8}=-0.22 \pm 0.11, p=0.05\right)$, indicating that outliers were significantly affecting the results of the earlier analysis (see Table 8). Moreover, this finding agreed more closely to that of the discontinuous analysis, again providing evidence for differential genetic etiology of reading disability as a function of math scores.

Table 8. Fit of extended regression model to proband and control transformed READ scores based on continuous MATH scores following outlier analysis

\begin{tabular}{llrrr}
\hline Coefficient & Interpretation & Estimate $\pm \mathrm{SE}$ & \multicolumn{1}{c}{$t$} \\
\hline $\mathrm{B}_{2}$ & Estimate of $\mathrm{h}_{\mathrm{g}}^{2}$ when $\mathrm{M}=0$ & $0.15 \pm 0.25$ & 0.61 & 0.5419 \\
$\mathrm{~B}_{5}$ & Estimate of linear effect of math group on $\mathrm{h}_{\mathrm{g}}^{2}$ & $-0.68 \pm 0.35$ & -1.95 & 0.0512 \\
$\mathrm{~B}_{8}$ & Estimate of quadratic effect of math group on $\mathrm{h}_{\mathrm{g}}^{2}$ & $-0.22 \pm 0.11$ & -1.96 & 0.0500 \\
\hline
\end{tabular}

\section{DISCUSSION}

The present study employed quantitative genetic analyses of twin data to validate the differential diagnosis of reading disability as a function of mathematics performance. First, $\mathrm{MZ}$ and $\mathrm{DZ}$ probandwise concordance rates for reading disability were compared for groups that differed on standardized 
math scores. Significant differences were found between the $\mathrm{MZ}$ and $\mathrm{DZ}$ concordance rates in each of the three groups, suggesting a genetic influence on reading disability. Moreover, the magnitude of concordance rates varied across the three groups, suggesting the possibility of differential etiology across groups.

The second approach employed an extension of the DeFries \& Fulker (1985, 1988) regression model which tests for differential heritability as a function of a given covariate. When twin pairs were divided into three groups based on their math scores, the significance of the interaction between the coefficient of relationship and the squared contrast code for the math group indicates that heritability of reading disability differs as a function of math scores for these three groups. The heritability estimates obtained were $0.35,0.75$, and 0.38 for the groups classified as not math-disabled, borderline mathdisabled, and math-disabled, respectively.

When the regression model was fitted to reading performance data and the continuous math scores, rather than the contrast-coded groups, the term coding for differential heritability as a function of squared math score was not significant. Because outliers are obviously more problematic for analyses of continuous data than for those of discontinuous measures, the data were examined for possible outliers. When the data were reanalyzed after several outliers that had a disproportionate effect on the bivariate relationship were omitted, the term coding for differential heritability as a quadratic function of math score was significant. Thus, results of both the discontinuous and continuous analyses indicate that the etiology of reading deficits may differ as a function of mathematics performance. Of course, if different tests had been used to assess mathematics deficits (e.g., tests involving computational skills in a paper and pencil format), different results might have been obtained.

In conclusion, the findings of the present study suggest that heritable influences on reading disability may be especially salient for children with borderline mathematic performance deficits. Although this evidence for a differential etiology is tentative given the present sample size and the limited tests of mathematics, these results support the position of Fletcher et al. (1993) that math performance may be a valid dimension for diagnosing subgroups of reading disability. Furthermore, these results illustrate how tests for differential etiology may be employed to develop a more reliable and valid classification system for learning disabilities.

\section{ACKNOWLEDGMENTS}

This work was supportcd in part by program project and center grants from NICHD (HD-11681 and HD-27802) to J. C. DeFries. This report was prepared while S. Casto was supported by NIMH training grant MH16880. The invaluable contributions of the many Colorado school districts and of the families who participated in this study are gratefully acknowledged. 


\section{REFERENCES}

Bakwin, H. (1973). Reading disability in twins, Developmental Medicine and Child Neurology 15: 184-187.

DeFries, J. C. (1985). Colorado Reading Project. In: D. Gray \& J. Kavanagh (eds.), Biobehavioral measures of dyslexia (pp. 107-122). Parkton, MD: York Press.

DeFries, J. C. \& Fulker, D. W. (1985). Multiple regression analysis of twin data, Behavior Genetics 15: 467-473.

DeFries, J. C. \& Fulker, D. W. (1988). Multiple regression analysis of twin data: Etiology of deviant scores versus individual differences, Acta Geneticae Medicae et Gemellolgiae 37: 205-216.

DeFries, J. C., Fulker, D. W. \& LaBuda, M. C. (1987). Evidence for a genetic aetiology in reading disability of twins, Nature $329: 537-539$.

DeFries, J. C. \& Gillis, J. J. (1991). Etiology of reading deficits in learning disabilities: Quantitative genetic analysis. In: J. E. Obrzut \& G. W. Hynd (eds.), Neuropsychological foundations of learning disabilities: A handbook of issues, methods, and practice (pp. 29-47). Orlando, FL: Academic Press.

DeFries, J. C. \& Gillis, J. J. (1993). Genetics of reading disability. In: R. Plomin \& G. E. McClearn (eds.), Nature, nurture, and psychology (pp. 121-145). Washington, DC: American Psychological Association.

Dunn, L. M. \& Markwardt, F. C. (1970). Examiner's manual: Peabody Individual Achievement Test. Circle Pines, MN: American Guidance Services.

Fletcher, J. M. (1985). External validation of learning disability typologies. In: B. P. Rourke (ed.), Neuropsychology of learning disabilities: Essentials of subtype analysis (pp. 187-211). New York: Guilford Press.

Fletcher, J. M., Francis, D. J., Rourke, B. P., Shaywitz, S. E. \& Shaywitz, B. A. (1993). Classification of learning disabilities: Relationships with other childhood disorders. In: G. R. Lyon, D. B. Gray, J. F. Kavanagh \& N. A. Krasnegor (eds.), Better understanding learning disabilities: New views from research and their implications for education and public policies (pp. 27-55). Baltimore: Paul H. Brookes Publishing.

Fletcher, J. M., Morris, R. D. \& Francis, D. J. (1991). Methodological issues in the classification of attention-related disorders, Journal of Learning Disabilities 24: 72-77.

Judd, C. M. \& McClelland, G. H. (1989). Data analysis: A model comparison approach. San Diego, CA: Harcourt Brace Jovanovich.

LaBuda, M. C., DeFries, J. C. \& Fulker, D. W. (1986). Multiple regression analysis of twin data obtained from selected samples, Genetic Epidemiology 3: 425-433.

Light, J. G. \& DeFries, J. C. (1995). Comorbidity of reading and mathematics disabilities: Genetic and environmental etiologies, Journal of Learning Disabilities 28: 96106.

Lyon, G. R. (1993). Preface. In: G. R. Lyon, D. B. Gray, J. F. Kavanagh \& N. A. Krasnegor (eds.), Better understanding learning disabilities: New views from research and their implications for education and public policies (pp. xvii-xix). Baltimore, MD: Paul H. Brookes Publishing.

Nichols, R. C. \& Bilbro, W. C. (1966). The diagnosis of twin zygosity, Acta Genetica et Statistica Medica 16: 265-275.

Pennington, B. F., Gilger, J. W., Olson, R. K. \& DeFries, J. C. (1992). The external validity of age-versus IQ-discrepancy definitions of reading disability: Evidence from a twin study, Journal of Learning Disabilities 25: 562-573.

Rourke, B. P. (1989). Nonverbal learning disabilities: The syndrome and the model. New York: Guilford Press.

Siegel, L. S. \& Heaven, R. K. (1986). Categorization of learning disabilities. In: S. J. Ceci (ed.), Handbook of cognitive, social, and neuropsychological aspects of learning disabilities (pp. 95-121). Hillsdale, NJ: Erlbaum.

Stevenson, J., Graham, P., Fredman, G. \& McLoughlin, V. (1984). The genetics of reading dis- 
ability. In: C. J. Turner \& H. B. Miles (eds.), The biology of human intelligence (pp. 85-97). Nafferton Books.

Stevenson, J., Graham, P., Fredman, G. \& McLoughlin, V. (1987). A twin study of genetic influences on reading and spelling ability and disability, Journal of Child Psychology and Psychiatry 28: 229-247.

Strang, J. D. \& Rourke, B. P. (1985). Arithmetic disability subtypes: The neuropsychological significance of specific arithmetical impairment in childhood. In: B. P. Rourke (ed.), Neuropsychology of learning disabilities: Essentials of subtype analysis (pp. 167-183). New York: Guilford Press.

Wechsler, D. (1974). Examiner's manual: Wechsler Intelligence Scale for Children-Revised. San Antonio, TX: Psychological Corporation.

Wechsler, D. (1981). Examiner's manual: Wechsler Adult Intelligence Scale-Revised. San Antonio, TX: Psychological Corporation.

Address for correspondence: John C. DeFries, Institute for Behavioral Genetics, University of Colorado, Campus Box 447, Boulder, CO 80309-0447, USA

Phone: (303) 492-2817; Fax: (303) 492-8063; E-mail: john.defries@colorado.edu 